\title{
DESINVESTIMENTO INDUSTRIAL E AS REgIÕES PORTUGUESAS. REFLEXOS DA MUDANÇA NO ESPAÇO ECONÓMICO INTERNACIONAL ${ }^{1}$
}

\author{
MÁRIO VALE ${ }^{2}$ \\ RUi Dias ${ }^{3}$
}

\begin{abstract}
Resumo - A mobilidade crescente do capital, especialmente de origem estrangeira, tem vindo a revelar-se preocupante para a economia das regiões e para a vida das comunidades. Até certo ponto, o investimento é uma opção estratégica das empresas idêntica ao desinvestimento, embora os seus impactos sejam necessariamente diferentes. O desinvestimento em certas actividades é mesmo considerado como uma condição necessária para a mudança estrutural da base económica das regiões. No entanto, o desfasamento temporal entre fluxos de destruição e criação de actividades origina, frequentemente, problemas económicos e sociais nos territórios.

O artigo inicia-se com uma discussão acerca da problemática do desinvestimento. Em seguida, efectua-se uma análise da evolução recente do emprego e do produto industrial em Portugal. O ponto seguinte trata do estudo dos fluxos de criação e destruição de emprego, numa óptica sectorial e territorial, procurando identificar e explicar a diferenciação das trajectórias regionais. Finalmente, apontam-se casos específicos de desinvestimento estrangeiro, ocorridos recentemente em Portugal, que ilustram não só a perspectiva micro-económica do desinvestimento mas também as mudanças em curso em cadeias de valor globais, levando-nos a equacionar o (re)posicionamento do país na divisão internacional do trabalho.
\end{abstract}

Palavras-chave : Desinvestimento, reestruturação industrial, assimetrias regionais, emprego, Portugal.

Abstract - industrial diVESTMENT AND PORTUgUese Regions Within the CHANGES IN THE INTERNATIONAL ECONOMIC SPACE. The spatial impacts of capital mobility, especially foreign capital, are becoming increasingly complex and are

1 Investigação apoiada pelo projecto «DivesT - Desinvestimento e Impactos Económicos, Sociais e Territoriais», financiado pela Fundação para a Ciência e Tecnologia com comparticipação do FEDER (POCTI/GEO/34037/2000).

2 Centro de Estudos Geográficos da Universidade de Lisboa. E-mail: mario.vale@mail.doc.fl.ul.pt

3 Centro de Estudos Geográficos da Universidade de Lisboa. E-mail: ruidias@mail.vis.fl.ul.pt 
often critical to the economies of regions and local community life. To a certain extent, divestment is, in essence, another strategic option of firms and it may not be necessarily negative for regions. Still, the impacts are not identical to investment. In economic analysis, divestment in certain activities is seen as necessary to achieve regional economic restructuring. However, the time gap between the creation and destruction of activities frequently causes social and economic problems in regions.

Starting with a conceptual framework of divestment, we then analyse the recent evolution of industrial employment and product in order to provide a macro-economic framework for the analysis of employment creation and destruction flows that follows. This analysis has a sectorial and regional perspective aimed at identifying different paths by regions. Finally, specific cases of foreign divestment, which have recently occurred in Portugal, are discussed, illustrating not only a micro-economic perspective of divestment but also the changes in the global value chains that point to a (re)positioning of the country in the international division of labour.

Key words: Divestment, industrial restructuring, regional disparities, employment, Portugal.

\section{INTRODUÇÃO}

Os ciclos de expansão/recessão económica têm marcado a evolução do sistema capitalista, condicionando a vida dos trabalhadores, famílias e, num sentido mais amplo, das comunidades. As regiões são confrontadas com uma mobilidade crescente do capital num quadro de integração económica e de drástica redução dos custos de transporte e de comunicação. No entanto, a mudança nem sempre decorre no sentido da valorização dos activos da empresa ou da criação de novas competências.

Em Portugal, têm surgido notícias nos media de encerramentos de estabelecimentos industriais, deslocalização da produção, despedimentos em massa, salários em atraso, etc., relatando casos de empresas de origem estrangeira e de pequenas e médias empresas nacionais, ainda que os primeiros suscitem compreensivelmente maior interesse na opinião pública. Este fenómeno é também observado noutros países, sobretudo o downsizing de grandes empresas multinacionais. Veja-se, por exemplo, os casos da AT\&T, IBM, GM, Boeing, Delta Airlines ou, mais recentemente, da Philips, Motorola, Ericsson. As administrações das multinacionais, sob pressão dos principais accionistas, têm vindo a eleger estratégias de downsizing, que visam aumentar o valor das acções das empresas nas praças financeiras.

Verificam-se, no entanto, importantes assimetrias espaciais em relação às dinâmicas de investimento e de emprego. A dotação dos factores de produção revela especificidades historicamente construídas que parecem condicionar 
o destino dos territórios e influenciar o seu papel numa economia global. Enquanto algumas regiões aproveitam com sucesso as novas oportunidades - as regiões "ganhadoras» (BENKO e LIPIETZ, 1992) - outras atravessam períodos de recessão económica, pelo que necessitam de assistência pública para a sua regeneração. O Nordeste de Inglaterra, a bacia do Ruhr, a área industrializada do Nordeste de França, o Nordeste dos EUA são algumas das regiões que atravessaram uma forte recessão económica derivada da desindustrialização da base económica (Blackaby, 1981; Bluestone e Harrison, 1982).

$\mathrm{Na}$ verdade, a redução ou encerramento da actividade é uma das possibilidades de gestão estratégica e não é necessariamente negativa para a região. A lógica schumpeteriana da inovação tecnológica origina o desenvolvimento de novas actividades e também a destruição de outras, conduzindo, no entanto, a uma melhoria da situação económica e social dos territórios. O desinvestimento é, deste modo, um processo tão natural como o investimento. Todavia, a descoincidência temporal entre a destruição e a criação de novas actividades origina, na maior parte das vezes, problemas económicos e sociais nos territórios. A situação é ainda mais preocupante quando o encerramento de um estabelecimento resulta de uma estratégia empresarial de transferência de capital para outras regiões, na busca de condições mais vantajosas, mormente custos de trabalho mais reduzidos. A transferência espacial de capital é, deste modo, o resultado de estratégias das multinacionais num tempo de liberalização e de internacionalização da economia. No caso dos EUA, este processo atingiu uma escala ímpar logo a partir dos anos 1970, tendo BLUESTONE e HARRISON (1982) argumentado que a América estava a entrar numa fase de desindustrialização, que definiam como um desinvestimento generalizado e sistemático na capacidade produtiva de base da nação.

A questão central que procuramos discutir neste artigo é saber em que medida o declínio da actividade industrial traduz um caso de desinvestimento sistemático e generalizado na capacidade produtiva de base em Portugal. É uma questão complexa porque são múltiplas as dimensões analíticas a considerar; desde logo importa avaliar a relevância de factores económicos de âmbito geral (especificidades tecnológicas, mercados, custo do trabalho) e particular (gestão empresarial), bem como factores sócio-territoriais (mercado de trabalho, acessibilidades, externalidades) para o processo de desinvestimento. Deste modo, o artigo inicia-se com uma discussão acerca do significado, tipos e factores do desinvestimento. Em seguida, caracteriza-se a evolução recente do emprego e do produto industrial no país, de modo a enquadrar a análise dos fluxos de criação e destruição de emprego, numa perspectiva sectorial e regional, procurando identificar diferentes tipos de trajectórias. Finalmente, apontam-se casos específicos de desinvestimento estrangeiro, ocorridos recentemente em Portugal, tendo por objectivo discutir simultaneamente as mudanças em curso em cadeias de valor globais e o (re)posicionamento do país na divisão internacional do trabalho. 


\section{DESINVESTIMENTO: SIGNIFICADO, TIPOS E FACTORES ${ }^{4}$}

Em termos gerais, o desinvestimento é um fenómeno tão natural como o investimento (Freitas, 1988). Mariotti e Piscitello (1997) admitem que o desinvestimento é uma das medidas possíveis de gestão empresarial. Salientam, contudo, a dificuldade em adoptá-la devido ao seu carácter negativo, frequentemente associado a um fracasso. Esta é uma das razões que justifica o tratamento reservado da informação relativa ao desinvestimento pelas empresas, circunstância que limita a elaboração de estudos empíricos acerca do tema. Antes de apresentar uma definição para o conceito de desinvestimento, deve salientar-se que, segundo WATTS e STAFFORD (1986), este pode ser involuntário ou ter origem numa decisão estratégica deliberada por um agente económico, sendo este mais comum no caso das empresas multi-estabelecimento. Benito (1997) e LaRIMO (1997) identificam ainda o desinvestimento forçado, que corresponde aos casos de nacionalizações, expropriações, confiscações,...

Alguns autores da área da economia e da gestão procuraram definir o conceito de desinvestimento, observando-se uma convergência em relação ao seu significado. Assim, por desinvestimento pode entender-se a liquidação voluntária ou venda da totalidade ou parte substancial de uma operação activa de uma empresa, cuja decisão é baseada em considerações estratégicas (BoDDEWYN, 1979) ou, como afirmam WATTS e STAFFORD (1986), tem um carácter involuntário que configura um caso de fracasso. O desinvestimento refere-se, assim, à alienação de uma parcela significativa ou da totalidade dos activos (DuHAImE e GRANT, 1984), pelo que diz respeito ao desmantelamento de uma relação de propriedade.

Na óptica da geografia, a definição de desinvestimento centrada nas relações de propriedade apresenta algumas limitações. Primeiro, a alienação total ou parcial de activos da empresa não implica necessariamente uma alteração no volume de produção ou de emprego, pelo que os seus efeitos espaciais serão nulos ou negligenciáveis. Na verdade, não se trata de um desinvestimento sob o ponto de vista territorial. Segundo, e em oposição ao primeiro argumento, as regiões podem sentir o desinvestimento sem decorrer uma alienação da propriedade. Alguns exemplos ajudam a clarificar o significado destes comentários. A saída recente da Ford da joint venture Autoeuropa ilustra um caso de alteração da propriedade sem quaisquer efeitos negativos na economia da região, enquanto a redução sistemática do ritmo da produção na Siderurgia Nacional até ao seu encerramento decorreu sem alterações significativas, pelo menos mais recentemente, das relações de propriedade (SoARES, 2001). No entanto, a dimensão da propriedade não pode ser descurada numa análise do desinvestimento, pelo facto da decisão se reportar à empresa e não ao estabelecimento. A distinção entre empresa e estabelecimento parece essencial para a compreen-

4 Este ponto baseia-se numa comunicação apresentada por um dos autores (VALE, 2001). 
são do significado do desinvestimento. Se, por um lado, a decisão depende da empresa, repercutindo-se no estabelecimento, por outro lado, é ao nível do estabelecimento que a implementação de eventuais decisões de alteração do produto, produtividade e emprego, se reflectem no território que, em retroacção, influencia o desempenho do estabelecimento e, assim, indirectamente o próprio processo de tomada de decisão da empresa.

Num estudo recente sobre o desinvestimento, SimóEs (2001) identifica os principais tipos de operações de desinvestimento, partindo do cruzamento de duas dimensões: a propriedade, que traduz a perspectiva tradicional do estudo do desinvestimento, e a actividade ao nível do estabelecimento, que se relaciona directamente com a envolvente espacial (quadro I).

$\mathrm{Na}$ verdade, o primeiro tipo não é uma operação de desinvestimento, mantendo-se a relação de propriedade e a actividade do estabelecimento. O segundo tipo traduz uma situação de manutenção da actividade e de alienação total ou parcial da participação em favor de outro agente económico. Neste

Quadro I - Tipologia de operações de desinvestimento.

Table I - Typology of divestment operations.

\begin{tabular}{|c|c|c|}
\hline 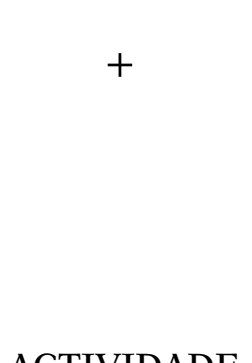 & Sem impacto económico e espacial & $\begin{array}{l}\text { Desinvestimento «forçado» } \\
\text { Venda da filial } \\
\text { Abandono de posição em joint } \\
\text { venture } \\
\text { MBO } \\
\text { Alienação parcial da } \\
\text { participação no capital } \\
\qquad 2\end{array}$ \\
\hline & $\begin{array}{l}\text { Recessão in situ } \\
\text { Obsolescência tecnológica } \\
\text { Declínio da produção } \\
\text { (fim da actividade produtiva/ } \\
\text { orientação do negócio para } \\
\text { actividades de baixo valor } \\
\text { acrescentado) }\end{array}$ & $\begin{array}{l}\text { Encerramento da fábrica } \\
\text { Venda de participação com } \\
\text { redução ou desvalorização de } \\
\text { actividade (downgrading) }\end{array}$ \\
\hline- & 4 & 3 \\
\hline
\end{tabular}

Adaptado de SIMõES (2001: 99) 
caso, também não se observa necessariamente um desinvestimento na óptica territorial mas apenas na perspectiva da empresa. As formas que ilustram este tipo de operação compreendem a venda do estabelecimento a terceiros, venda da posição em joint venture, MBO e alienação parcial da participação. O terceiro tipo de operação de desinvestimento configura tipicamente o encerramento de unidades, traduzido pela ausência de actividade económica e pela liquidação do estabelecimento. É, sem dúvida, o caso extremo de desinvestimento, quer na óptica empresarial, quer na territorial. Finalmente, o último tipo de operação de desinvestimento na proposta de SIMÕES (2001) diz respeito à redução da actividade, mantendo-se, porém, a relação de propriedade. Traduz as situações de obsolescência tecnológica, recessão ou até abandono da actividade produtiva em favor de outras actividades de menor valor acrescentado, como a armazenagem e distribuição. Os impactos espaciais desta operação de desinvestimento podem ter significado para a economia da região e para o mercado de trabalho local.

Num trabalho anterior, foi apresentada uma proposta de tipologia do desinvestimento numa óptica espacial (VALE, 2001). Partindo da tipologia de SIMÕES (2001), acrescentaram-se outras duas dimensões de análise: a motivação e a intensidade do impacto espacial. Do cruzamento das dimensões actividade, propriedade, motivação e impacto territorial, chega-se a uma tipologia do desinvestimento segundo uma lógica territorial (quadro II).

As duas primeiras categorias dizem respeito ao desinvestimento derivado da transferência da capacidade produtiva, devendo-se as principais diferenças à

Quadro II - Tipologia do desinvestimento e impactos espaciais.

Table II - Typology of divestment and spatial impacts.

\begin{tabular}{|c|c|c|c|c|c|}
\hline ACTIVIDADE & PROPRIEDADE & MOTIVAÇÃO & \multicolumn{2}{|c|}{ IMPACTO ESPACIAL } & TIPO \\
\hline $\begin{array}{c}\text { Cessação } \\
\text { de actividade }\end{array}$ & $\begin{array}{l}\text { Abandono do } \\
\text { estabelecimento } \\
\text { e manutenção } \\
\text { da empresa }\end{array}$ & $\begin{array}{l}\text { Decisão } \\
\text { estratégica } \\
\text { voluntária }\end{array}$ & \multirow{2}{*}{$\begin{array}{c}\text { Transferência } \\
\text { da capacidade } \\
\text { produtiva } \\
\text { (operações) }\end{array}$} & Total & Deslocalização I \\
\hline $\begin{array}{c}\text { Redução } \\
\text { da actividade / } \\
\text { especializaçãao / } \\
\text { reestruturação }\end{array}$ & $\begin{array}{l}\text { Manutenção do } \\
\text { estabelecimento } \\
\text { e da empresa }\end{array}$ & $\begin{array}{c}\text { Decisão } \\
\text { estratégica } \\
\text { voluntária }\end{array}$ & & $\begin{array}{c}\text { Parcial } \\
\text { (segmentação } \\
\text { da produção / } \\
\text { produto) }\end{array}$ & Deslocalização II \\
\hline $\begin{array}{c}\text { Cessação } \\
\text { da actividade }\end{array}$ & $\begin{array}{l}\text { Abandono do } \\
\text { estabelecimento } \\
\text { e dissolução } \\
\text { da empresa }\end{array}$ & \begin{tabular}{|c|} 
Decisão \\
involuntária / \\
Fracasso
\end{tabular} & \multirow{2}{*}{$\begin{array}{c}\text { Diminuição } \\
\text { da actividade } \\
\text { produtiva } \\
\text { sem } \\
\text { transferência }\end{array}$} & Total & Encerramento \\
\hline $\begin{array}{c}\text { Recessão / } \\
\text { reestruturação }\end{array}$ & $\begin{array}{l}\text { Manutenção do } \\
\text { estabelecimento } \\
\text { e da empresa }\end{array}$ & $\begin{array}{c}\text { Decisão } \\
\text { estratégica } \\
\text { voluntária / } \\
\text { Fracasso }\end{array}$ & & Parcial & Regressão in situ \\
\hline
\end{tabular}

Adaptado de VALE (2001: 276) 
intensidade do impacto na região. A deslocalização de tipo I expressa as situações de cessação da actividade e cedência ou abandono das instalações, ou seja, observa-se uma transferência de todo o processo produtivo para outro local. A deslocalização de tipo II traduz a transferência de uma parte da capacidade instalada para outro local, mantendo-se, assim, uma parte da actividade produtiva na região. Registe-se ainda uma situação distinta em relação à dimensão propriedade; no primeiro caso, ocorre sempre a alienação, por venda ou abandono, das instalações pela empresa, enquanto no segundo tipo de deslocalização se mantém o vínculo de posse. Nesta situação, trata-se de uma empresa multi-estabelecimentos que decide alargar a capacidade produtiva num outro estabelecimento. A escala espacial da deslocalização compreende os níveis intra-regional, inter-regional e internacional em ambos os tipos de deslocalização. Os movimentos de capital para o estrangeiro ou para outras regióes com menores níveis salariais revelam-se mais preocupantes para a economia local/regional.

$\mathrm{O}$ encerramento e a regressão in situ ilustram as categorias de desinvestimento com um impacto geralmente negativo para a empresa e para a região. Também nestes dois tipos se verifica uma desigual intensidade do impacto espacial, claramente mais profundo no caso do encerramento. A regressão in situ pode anteceder o encerramento, embora também possa traduzir uma reestruturação do estabelecimento, ainda que tal seja menos frequente. É por esta razão que estes dois tipos de desinvestimento representam, em geral, situações de fracasso quer na óptica da empresa quer na do território.

Tendo discutido os tipos de desinvestimento, importa reflectir sobre os seus factores. Os estudos especificamente desenvolvidos sobre este tema apontam para a existência de factores de desinvestimento internos e externos à unidade produtiva (Bluestone e Harrison, 1982; Massey e MeEgan, 1982; Massey, 1984; Martin e RowTHORn, 1986; Watts e StafFord, 1986; WatTs, 1991; Maclachlan, 1992; Benito, 1997; Clark e Wrigley; 1997; Simôes, 2001; Vale, 2001). Os factores internos de maior ponderação são tipicamente a obsoles-cência tecnológica, o fim do ciclo de vida do produto e as dificuldades de gestão da força de trabalho. Por outro lado, a perda de quota de mercado, o aumento dos salários e a falta de mão-de-obra qualificada no mercado de trabalho local, o congestionamento das infra-estruturas, a concorrência entre diversos estabelecimentos da empresa ou grupo económico, a expectativa de mais valias derivadas da venda do solo para outros usos e a competitividade inter-regional pela atracção de novos investimentos são, no conjunto mas de forma desigual, os principais factores externos ao estabelecimento que maior influência têm na decisão de desinvestimento.

Os factores de desinvestimento combinam aspectos internos e externos às unidades produtivas. A expressão espacial das diversas formas de desinvestimento constitui uma das perspectivas de investigação geográfica sobre o tema, privilegiando-se, neste caso, uma análise agregada das variações de emprego e produto industrial. Nesta perspectiva, destacam-se os espaços de regressão da actividade industrial, entendendo-se este facto como uma consequência da 
conjugação da inovação tecnológica no sector, das mudanças na procura e da alteração das divisões espaciais do trabalho (MASSEY, 1984). Não se pode, portanto, discutir factores de desinvestimento internos às unidades produtivas, que ponderam aspectos como cultura da empresa, ciclo de vida do produto, nível tecnológico, gestão da força de trabalho. Os estudos de caso surgem, deste modo, como um complemento à análise agregada das variáveis económicas.

Neste artigo, combinam-se estas duas perspectivas de estudo de desinvestimento. Procede-se, deste modo, à análise da evolução do emprego e do produto e dos fluxos de criação e destruição de emprego, por forma a captar as transformações estruturais da base industrial e identificar os espaços de desinvestimento industrial no país, e apresentam-se, posteriormente, algumas conclusões sobre as principais operações de desinvestimento estrangeiro em Portugal. Pretende-se discutir até que ponto o encerramento destes estabelecimentos industriais reflecte um novo posicionamento de Portugal na divisão internacional do trabalho e uma redefinição do papel das empresas industriais nas cadeias de valor global.

\section{EVOLUÇÃO RECENTE DO EMPREGO E DO PRODUTO INDUSTRIAL EM PORTUGAL}

A partir dos dados constantes das Estatísticas das Empresas, publicadas pelo Instituto Nacional de Estatística (INE), avaliou-se a variação do emprego e produto industriais para o período 1990-2000, de modo a contextualizar a análise posterior dos fluxos de criação e destruição de emprego. Entendemos aqui emprego industrial como o somatório do emprego da indústria extractiva e da indústria transformadora. A compatibilização entre as duas revisões da Classificação das Actividades Económicas (CAE) seguiu, em grande parte, a proposta de trabalho de Costa e Costa (1996).

Considerando o volume total de emprego na indústria, verificamos uma tendência geral de diminuição (-8\%, entre 1990 e 2000), apesar de algumas flutuações de sinal contrário (fig. 1). Esta evolução global é o resultado de variações díspares ao nível dos vários ramos industriais, não obstante verificar-se

uma descida do emprego nos anos de menor crescimento económico, como os do período 1991-93 e, mais recentemente, 1999-2000.

Considerando a estrutura sectorial do emprego industrial (quadro III), observa-se que, em 1990, os têxteis e o vestuário se assumiam como os maiores empregadores industriais $(15,3 \%$ e $14 \%$, respectivamente). As indústrias alimentares, das bebidas e do tabaco empregavam $11,5 \%$ do total, seguindo-se a indústria da madeira e mobiliário (9\%), a fabricação de máquinas e equipamentos $(7,9 \%)$ e de produtos metálicos $(7,7 \%)$. Cumulativamente, estes sectores representavam 65,4\% do emprego industrial. No final do período considerado (2000), o ramo do vestuário revela-se o maior empregador relativamente ao total da indústria $(14,3 \%)$, seguido pelas indústrias da madeira e mobiliário, alimen- 


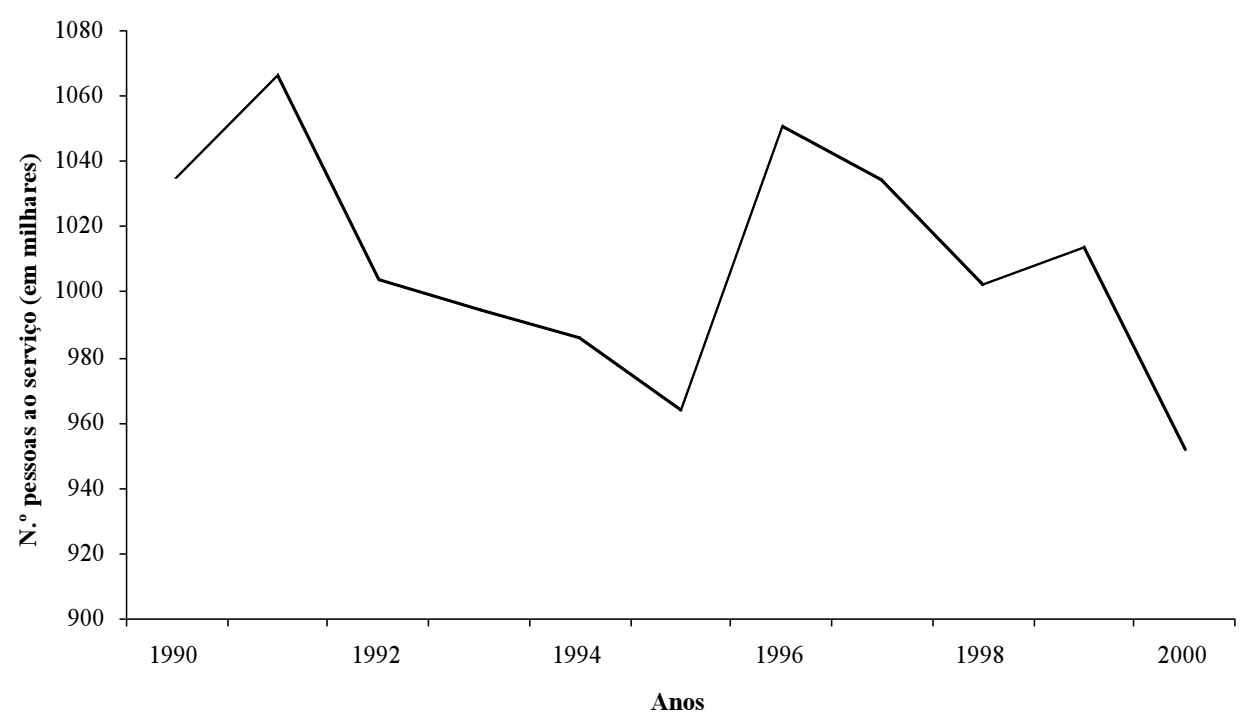

INE, Estatísticas das Empresas, 1990-2000

Fig. 1 - Evolução do número de pessoas ao serviço na indústria em Portugal, 1990-2000.

Fig. 1 -Evolution of the industrial employment in Portugal, 1990-2000.

tares, bebidas e tabaco (ambas com 11,2\%), e pelos têxteis (10,4\%). A fabricação de máquinas e equipamentos empregava $10,2 \%$ do total e a fabricação de produtos metálicos atinge os $8,5 \%$. Tomados em conjunto, estes sectores representam $65,8 \%$ do emprego industrial.

Como primeira constatação, salienta-se a subida do vestuário à categoria de principal ramo empregador, enquanto se observa uma importante descida da contribuição do têxtil, dada a quebra de $37,3 \%$ no volume absoluto de emprego desta actividade. Destaca-se também o maior peso da indústria da madeira e mobiliário, cujo emprego cresceu $15 \%$ no período considerado, e o da fabricação de máquinas e equipamentos no emprego industrial, consequência do seu crescimento em termos absolutos $(+19 \%)$.

Segundo a análise realizada por BAIRRADA (2000), não se observaram alterações significativas na estrutura da indústria transformadora em relação ao volume do emprego ao longo de 40 anos (1953-1993), existindo, contudo, alterações no posicionamento de cada um dos ramos de actividade. O têxtil, vestuário e calçado, madeira e cortiça, indústrias alimentares, bebidas e tabaco e ainda a fabricação de produtos metálicos, máquinas e material de transporte assumem-se como os sectores de maior importância (BAIRRADA, 2000). Reforça-se assim a ideia de que a estrutura do emprego industrial em Portugal assenta ainda em actividades que podemos designar como tradicionais, no sentido do menor 
Quadro III - Evolução da estrutura sectorial do emprego industrial em Portugal, 1990-2000.

Table III - Evolution of the sectoral structure of industrial employment in Portugal, 1999-2000.

\begin{tabular}{|c|c|c|}
\hline \multirow[b]{2}{*}{ Actividade industrial } & \multicolumn{2}{|c|}{$(\%$} \\
\hline & 1990 & 2000 \\
\hline Indústria Extractiva & 1,8 & 1,5 \\
\hline Indústrias Alimentares, das Bebidas e Tabaco & 11,5 & 11,2 \\
\hline Indústrias Têxteis & 15,3 & 10,4 \\
\hline Indústria do Vestuário & 14,0 & 14,3 \\
\hline Indústria do Calçado e Couro & 6,7 & 7,0 \\
\hline Indústria da Madeira e Mobiliário & 9,0 & 11,2 \\
\hline Indústria do Papel e Artes Gráficas & 5,0 & 5,4 \\
\hline Indústria Química & 6,3 & 5,2 \\
\hline Indústria dos Produtos Minerais não Metálicos & 7,1 & 7,5 \\
\hline Indústria Metalúrgica de Base & 2,0 & 1,5 \\
\hline Fabricação de Produtos Metálicos (excep. maq. e equip.) & 7,7 & 8,5 \\
\hline Fabricação de Máquinas e Equipamentos & 7,9 & 10,2 \\
\hline Fabricação de Material de Transporte & 3,8 & 4,2 \\
\hline Fabricação de Instrumentos Profissionais & 0,4 & 0,7 \\
\hline Outras Indústrias Transformadoras & 1,4 & 1,1 \\
\hline Total & 100,0 & 100,0 \\
\hline
\end{tabular}

INE, Estatísticas das Empresas, 1990-2000

input tecnológico que as caracteriza. Ocorreram, contudo, algumas alterações nos últimos anos. Estas dizem respeito, por um lado, à consolidação dos sectores da madeira e mobiliário e da fabricação de máquinas e equipamentos e, por outro lado, ao declínio evidente dos têxteis.

De modo a avaliar a evolução do produto industrial resolveu-se utilizar a variável Valor Acrescentado Bruto (VAB) a preços de mercado (pm). Podemos verificar que os ramos que mais contribuíram para a formação do VAB em 1990 foram a química $(20,8 \%)$, a alimentação, bebidas e tabaco $(13,9 \%)$, os têxteis $(10,8 \%)$, a fabricação de máquinas e equipamentos $(8,9 \%)$, os produtos minerais não metálicos $(7,8 \%)$ e o papel e artes gráficas $(7,2 \%)$. Estes sectores representavam no seu conjunto 69,4\% do produto industrial (quadro IV).

Em 2000, a fabricação de máquinas e equipamentos e as indústrias alimentares, bebidas e tabaco eram os maiores contribuintes para o VAB industrial $(12,1 \%$ e $12 \%$, respectivamente). A indústria química $(11,2 \%)$, do papel e artes gráficas $(10,2 \%)$, dos produtos minerais não metálicos $(10,1 \%)$ e a indústria da 
Quadro IV - Evolução da estrutura do produto industrial, por ramo, em Portugal, 1990-2000.

Table IV - Evolution of the structure of industrial product in Portugal, 1990-2000.

\begin{tabular}{|c|c|c|}
\hline \multirow[b]{2}{*}{ Actividade industrial } & \multicolumn{2}{|c|}{$(\%)$} \\
\hline & 1990 & 2000 \\
\hline Indústria Extractiva & 2,8 & 2,2 \\
\hline Indústrias Alimentares, das Bebidas e Tabaco & 13,9 & 12,0 \\
\hline Indústrias Têxteis & 10,8 & 7,3 \\
\hline Indústria do Vestuário & 6,4 & 6,6 \\
\hline Indústria do Calçado e Couro & 3,8 & 3,6 \\
\hline Indústria da Madeira e Mobiliário & 5,0 & 7,4 \\
\hline Indústria do Papel e Artes Gráficas & 7,2 & 10,2 \\
\hline Indústria Química & 20,8 & 11,2 \\
\hline Indústria dos Produtos Minerais não Metálicos & 7,8 & 10,1 \\
\hline Indústria Metalúrgica de Base & 2,3 & 2,2 \\
\hline Fabricação de Produtos Metálicos (excep. maq. e equip.) & 5,4 & 6,6 \\
\hline Fabricação de Máquinas e Equipamentos & 8,9 & 12,1 \\
\hline Fabricação de Material de Transporte & 3,8 & 6,9 \\
\hline Fabricação de Instrumentos Profissionais & 0,2 & 0,7 \\
\hline Outras Indústrias Transformadoras & 0,9 & 0,8 \\
\hline Total & 100,0 & 100,0 \\
\hline
\end{tabular}

INE, Estatísticas das Empresas, 1990-2000

madeira e do mobiliário $(7,4 \%)$ constituíam-se como os outros ramos principais dentro da indústria. No seu conjunto, somavam $63 \%$ do total de VAB industrial.

Deve destacar-se, neste período, o novo posicionamento da indústria da madeira e mobiliário, cujo produto cresceu a um ritmo duas vezes superior ao da média da indústria. A indústria química regista a maior queda, o que se verificou até em termos de valores a preços de mercado $(-8,7 \%)$, embora esta se tenha registado apenas nos dois últimos anos em análise e se prenda fundamentalmente com a descida abrupta na refinação de petróleo. Também é significativa a quebra continuada dos têxteis relativamente à sua contribuição para o produto industrial, ligeiramente inferior em 2000 à da indústria da madeira e mobiliário. Por outro lado, a fabricação de máquinas e equipamentos e a indústria do papel e artes gráficas viram crescer a sua importância relativamente ao total da indústria, registando o dobro do crescimento observado para o produto industrial.

Em suma, a estrutura industrial do país não apresenta diferenças profundas relativamente ao emprego e ao produto entre 1990 e 2000 . Todavia, a dimi- 
nuição do peso dos têxteis no emprego e da química no produto permitiram que outras actividades aumentassem o seu peso relativo na estrutura industrial, como as indústrias de calçado e couro, madeira e mobiliário e a fileira metálica.

\section{FLUXOS DE CRIAÇÃO E DESTRUIÇÃO DE EMPREGO}

\section{Dinâmicas industriais}

Com base na informação recolhida pelo Departamento de Estatística do Trabalho, Emprego e Formação Profissional (DETEFP), através dos Quadros de Pessoal, organizada numa base de dados específica ${ }^{5}$, pretendeu-se avaliar os fluxos de criação e destruição de emprego industrial. Por outro lado, a importância desta variável numa análise de impactos de desinvestimento é clara, pois é a que acarreta maiores problemas sociais. O período de análise estende-se de 1986 a 1998 e refere-se à criação de emprego em novos estabelecimentos (criados de novo mais os declarados pela primeira vez) e à destruição de emprego em estabelecimentos encerrados. Como referem Bluestone e Harrison (1982), os ganhos e as perdas associados com a abertura e encerramento ou relocalização de um estabelecimento são claramente o resultado de operações de investimento e desinvestimento. O mesmo não acontece com a expansão/ contracção de emprego em estabelecimentos existentes, sendo impossível destrinçar o que se deve a fenómenos de investimento ou desinvestimento. Em particular, relativamente à contracção de emprego em estabelecimentos que permanecem, podemos apenas inferir que poderá ter existido algum desinves-timento, mas não podemos quantificar directamente o seu impacto em termos de emprego.

A fonte estatística utilizada permite uma desagregação espacial ao nível da NUT III. Desta forma, apurou-se a informação relativa às variáveis referidas por ramo industrial e por NUT III. Convém advertir desde já que as diferenças residuais observadas entre os totais para a indústria dos dois tipos de balanços se deve a alguns registos que não estão referenciados a qualquer concelho na base de dados utilizada (DETEFP, 1999).

Como se pode observar na figura 2, o nível da destruição de emprego industrial em Portugal apresenta um ritmo de crescimento acentuado a partir de meados da década de 1980, assistindo-se a uma estabilização na primeira metade dos anos 1990. No último ano em análise, regista-se um forte aumento do fluxo de destruição do emprego, embora possa estar sobrevalorizado este valor, como refere o próprio DETEFP (1999), situação que pensava corrigir mais tarde através dos Quadros de Pessoal do ano seguinte. Se avaliarmos a evolução conjunta dos fluxos de destruição face aos de criação, observa-se que, até 1990,

5 DETEFP (1999) - Demografia dos Estabelecimentos em Portugal, 1982-1998. Lisboa. 


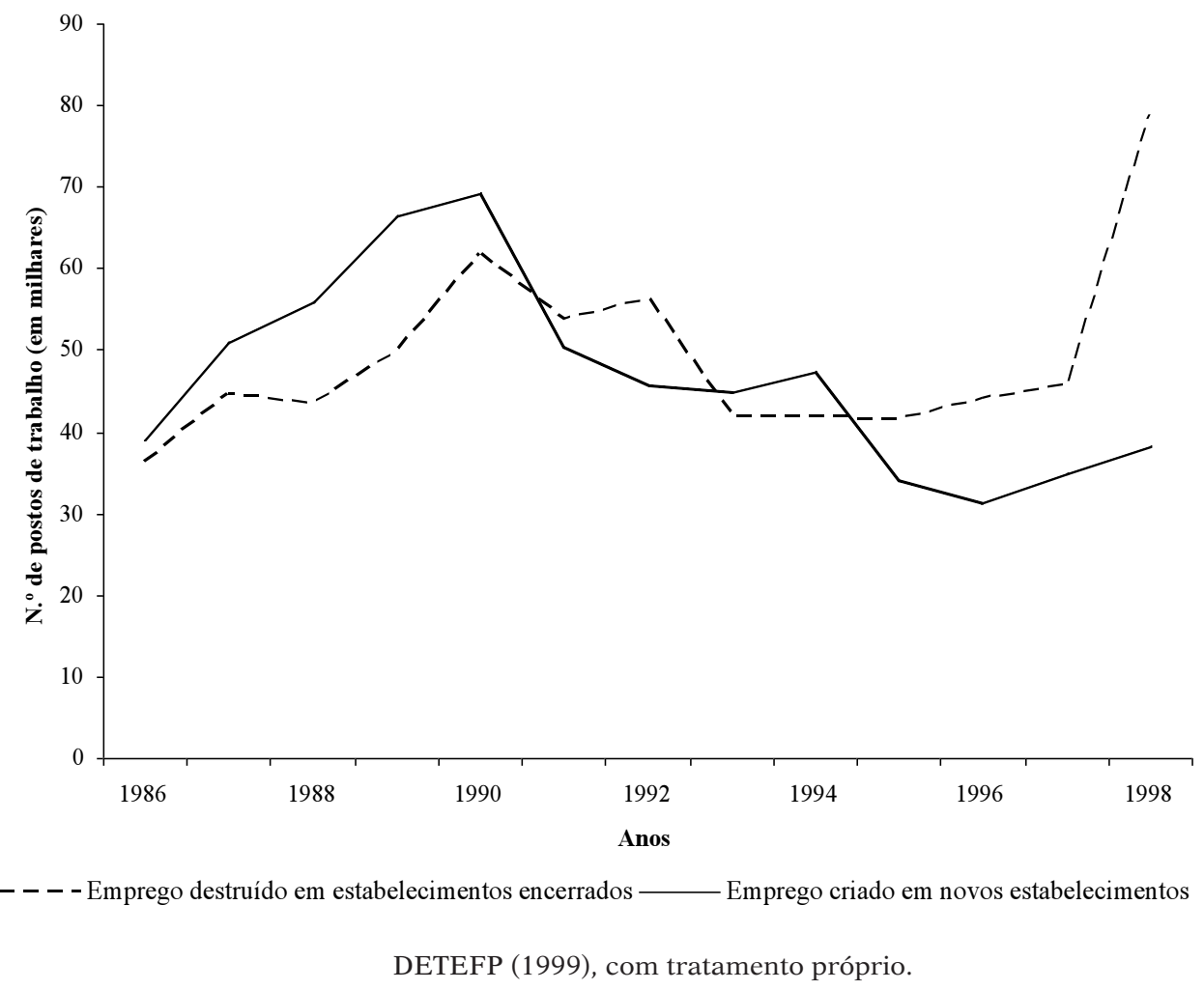

Fig. 2 - Fluxos de criação e destruição de emprego industrial em Portugal, 1986-1998.

Fig. 2 - Flows of industrial job creation and destruction in Portugal, 1986-1998.

o saldo era positivo, situação que só volta a acontecer excepcionalmente no biénio 1993-94, estabelecendo-se a partir daí uma situação em que o fluxo de destruição de emprego supera sempre o fluxo de criação de emprego.

É importante perceber também as diferenças entre os diversos ramos da indústria no que toca aos fluxos de criação e destruição de emprego (quadro V). Da observação do quadro, podemos identificar os têxteis como o ramo em que o saldo entre emprego criado e destruído foi mais negativo (cerca de 1 em cada 3 postos de trabalho), seguindo-se a indústria química, as indústrias alimentares, das bebidas e do tabaco, a fabricação de material de transporte, papel e artes gráficas e a metalúrgica de base. As indústrias de fabricação de produtos metálicos e do vestuário foram, por outro lado, os ramos que apresentaram maior saldo absoluto entre emprego criado e destruído entre 1986 e 1998.

Calculando taxas de destruição e criação de emprego para o período em estudo, tanto para o conjunto da indústria como para os vários ramos, face ao 
Quadro V - Fluxos absolutos de criação e destruição de emprego industrial, por ramo, em Portugal, 1986-1998.

Table $V$ - Absolute flows of industrial job creation and destruction by branch in Portugal, 1986-1998.

\begin{tabular}{|c|c|c|c|c|}
\hline Actividade industrial & $\begin{array}{c}\text { Volume de } \\
\text { emprego } \\
\text { (1986) }\end{array}$ & $\begin{array}{c}\text { Emp. destruído } \\
1986-98 \\
\text { (estab. encer.) }\end{array}$ & \begin{tabular}{|c|} 
Emp. criado \\
$1986-98$ \\
(novos \\
estab.) \\
\end{tabular} & $\begin{array}{l}\text { Saldo } \\
\text { líquido }\end{array}$ \\
\hline Indústria Extractiva & 14974 & 12166 & 12141 & -25 \\
\hline Indústrias Alimentares, das Bebidas e Tabaco & 95912 & 69696 & 63829 & -5867 \\
\hline Indústrias Têxteis & 161096 & 81762 & 60892 & -20870 \\
\hline Indústria do Vestuário & 90052 & 121106 & 124973 & 3867 \\
\hline Indústria do Calçado e Couro & 49340 & 49666 & 48786 & -880 \\
\hline Indústria da Madeira e Mobiliário & 82261 & 64621 & 65261 & 640 \\
\hline Indústria do Papel e Artes Gráficas & 46185 & 32916 & 29591 & -3325 \\
\hline Indústria Química & 62304 & 35024 & 28986 & -6038 \\
\hline Indústria dos Produtos Minerais não Metálicos & 61921 & 40172 & 41073 & 901 \\
\hline Indústria Metalúrgica de Base & 23608 & 9541 & 6919 & -2622 \\
\hline Fabricação de Produtos Metálicos (excep. maq. e equip.) & 68143 & 45343 & 52034 & 6691 \\
\hline Fabricação de Máquinas e Equipamentos & 64142 & 48068 & 47229 & -839 \\
\hline Fabricação de Material de Transporte & 38855 & 20677 & 17184 & -3493 \\
\hline Fabricação de Instrumentos Profissionais & 5379 & 1750 & 2185 & 435 \\
\hline Outras Indústrias Transformadoras & 10345 & 7402 & 7774 & 372 \\
\hline Total Indústria Transformadora & 859543 & 627744 & 596716 & -31028 \\
\hline Total & 874517 & 639910 & 608857 & -31053 \\
\hline
\end{tabular}

DETEFP (1999), com tratamento próprio.

volume global de emprego de cada um deles (quadro VI), podemos efectuar uma análise da importância relativa destes fluxos.

Como se pode observar, a taxa de destruição de emprego provocada pelo encerramento de estabelecimentos supera ligeiramente a de criação de emprego dos novos estabelecimentos para a globalidade do período em análise. O vestuário surge claramente como a actividade industrial em que a destruição de emprego foi maior relativamente ao stock de emprego. As indústrias extractivas, a indústria da madeira e mobiliário, a indústria do calçado do couro e ainda as alimentares, bebidas e tabaco apresentam valores superiores ao verificado para a média da indústria. Ao contrário, a actividade de fabricação de instrumentos profissionais registou uma taxa de destruição de emprego indiscutivelmente menor que o valor geral da indústria. Para melhor analisar o peso e importância ao nível da dinâmica sectorial deste emprego destruído temos de analisar a outra face da moeda, ou seja, a criação de emprego.

O vestuário é igualmente a actividade onde a taxa de criação de emprego foi substancialmente superior à média do sector industrial. As indústrias extractivas, da madeira e mobiliário e também as de calçado e couro apresentam um comportamento análogo a este. As actividades industriais que registam uma 
Quadro VI - Taxas globais de criação e destruição de emprego industrial, por ramo, em Portugal, 1986-1998.

Table VI - Global rates of industrial job creation and destruction by branch in Portugal, 1986-1998.

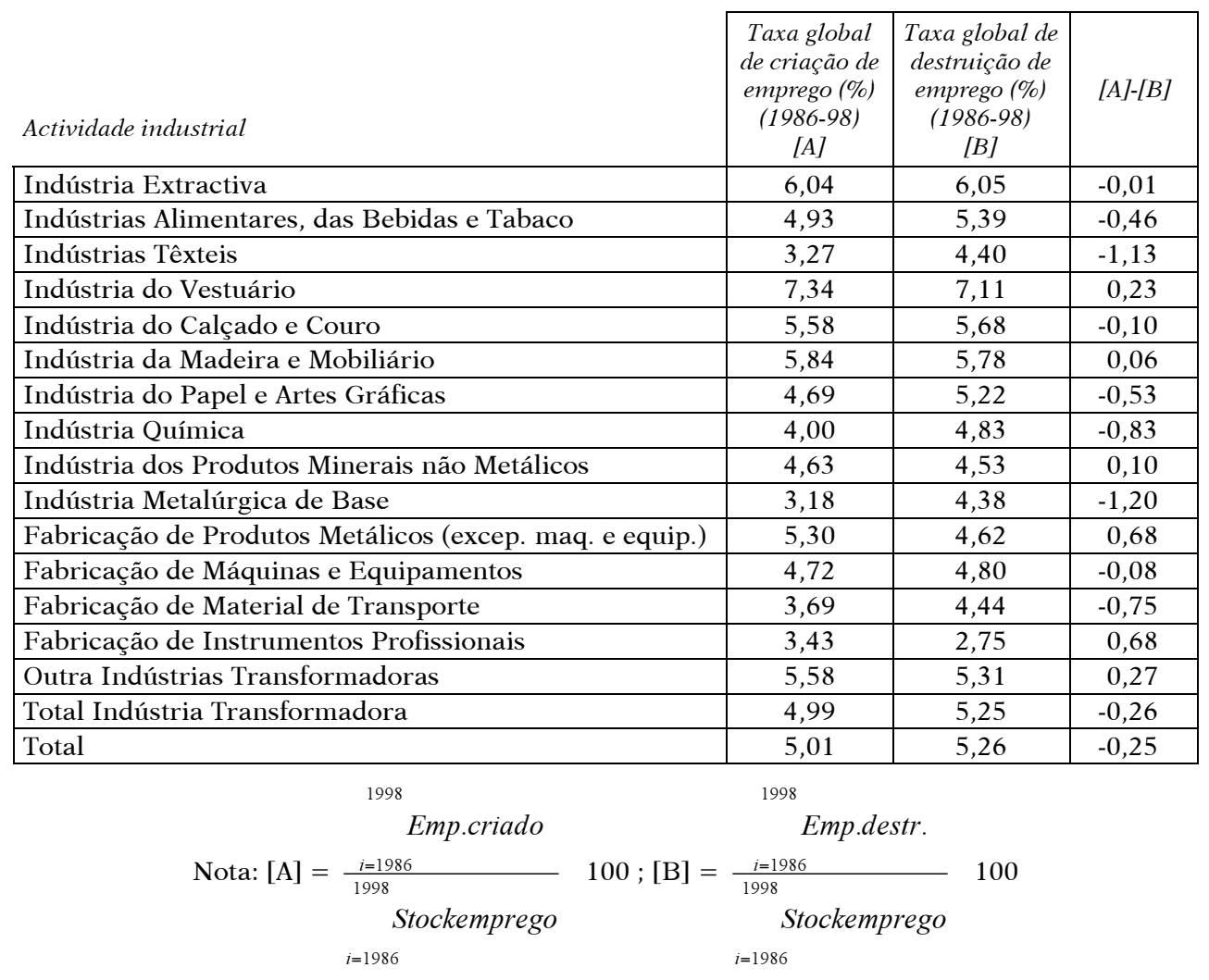

DETEFP (1999), com tratamento próprio.

menor dinâmica de criação de emprego são a metalurgia de base, os têxteis e a fabricação de instrumentos profissionais.

As dinâmicas de criação e de destruição de emprego foram, no entanto, muito diferenciadas entre as actividades industriais em Portugal no período em análise. Destacam-se três tipos de dinâmicas dominantes em relação ao comportamento dos fluxos de criação e de destruição de emprego.

Em primeiro lugar, a fabricação de produtos metálicos e de instrumentos profissionais foram das poucas actividades industriais que registaram um saldo positivo, ainda que a fabricação de instrumentos profissionais se destaque por um baixo nível de criação de emprego. Em segundo lugar, encontram-se as indústrias que apresentaram simultaneamente elevadas taxas de criação e de 
destruição de emprego, traduzindo um forte dinamismo empresarial acompanhado por níveis de sucesso reduzidos. As indústrias do vestuário e da madeira e mobiliário apresentam um fluxo relativamente elevado de criação de emprego, mas que acaba por ser de intensidade semelhante ao da destruição. Noutros casos, a dinâmica razoável de criação de emprego nem chega a compensar o emprego destruído, de que são exemplos a indústria extractiva, do calçado e couro e as alimentares, bebidas e tabaco, que traduzem uma situação onde o emprego destruído pelo encerramento de estabelecimentos é elevado relativamente ao stock de emprego, mas apenas ligeiramente superior ao emprego criado. Finalmente, a metalurgia de base, têxteis, química e material de transporte apresentaram comportamentos claramente regressivos em resultado da continuação do processo de reestruturação nos anos 1990, embora as taxas de criação e de destruição de emprego não tenham atingido os valores médios observados para a actividade industrial em Portugal.

A análise da evolução dos fluxos de destruição de emprego revela a existência de uma variabilidade inter-anual significativa para a generalidade dos ramos, à excepção das indústrias extractivas (fig. 3). Paralelamente, o vestuário parece decalcar, anos mais tarde, a evolução verificada nos têxteis, sendo estes dois ramos os mais importantes relativamente ao volume de emprego destruído.

A influência das indústrias têxtil e do vestuário no comportamento económico da indústria transformadora é bem evidente. Com efeito, estas actividades foram responsáveis por cerca de $2 / 3$ do emprego industrial destruído no período em análise, mas foram também as que criaram maior número de postos de trabalho em novos estabelecimentos (cerca de $31 \%$ do total). A crise da indústria têxtil contribuiu em cerca de $67 \%$ para o saldo negativo entre o emprego criado em novos estabelecimentos e o emprego destruído por encerramento de unidades na indústria transformadora entre 1986 e 1998.

Não se deve, segundo BESSA e VAZ (2002), confundir as causas da crise da fileira têxtil no início e no final do década de 1990; no primeiro período, a contracção da actividade relaciona-se com a obsolescência tecnológica e com o peso elevado de mão-de-obra envelhecida e com poucas qualificações, enquanto a crise actual decorre sobretudo da incapacidade das empresas valorizarem factores imateriais de competitividade, como o design, inovação, distribuição... Ou seja, reflecte o posicionamento de uma grande parte das empresas em actividades menos interessantes da cadeia de valor que estão sujeitas a uma forte concorrência dos países emergentes com baixos níveis salariais. Na verdade, as dificuldades de penetração em mercados externos e a integração de países de mão-de-obra mais barata nas redes de subcontratação internacionais têm vindo a afectar o desenvolvimento da indústria têxtil/vestuário em Portugal (PIRES, 1994).

A evolução descrita apresenta reflexos ao nível da produtividade do trabalho, devendo-se notar que o valor relativamente baixo da mesma para a indústria portuguesa, comparativamente a outros países da Europa Ocidental, se deve muito à própria estrutura industrial, em que as actividades de baixa ou média intensidade tecnológica concentram o maior número de postos de trabalho. 

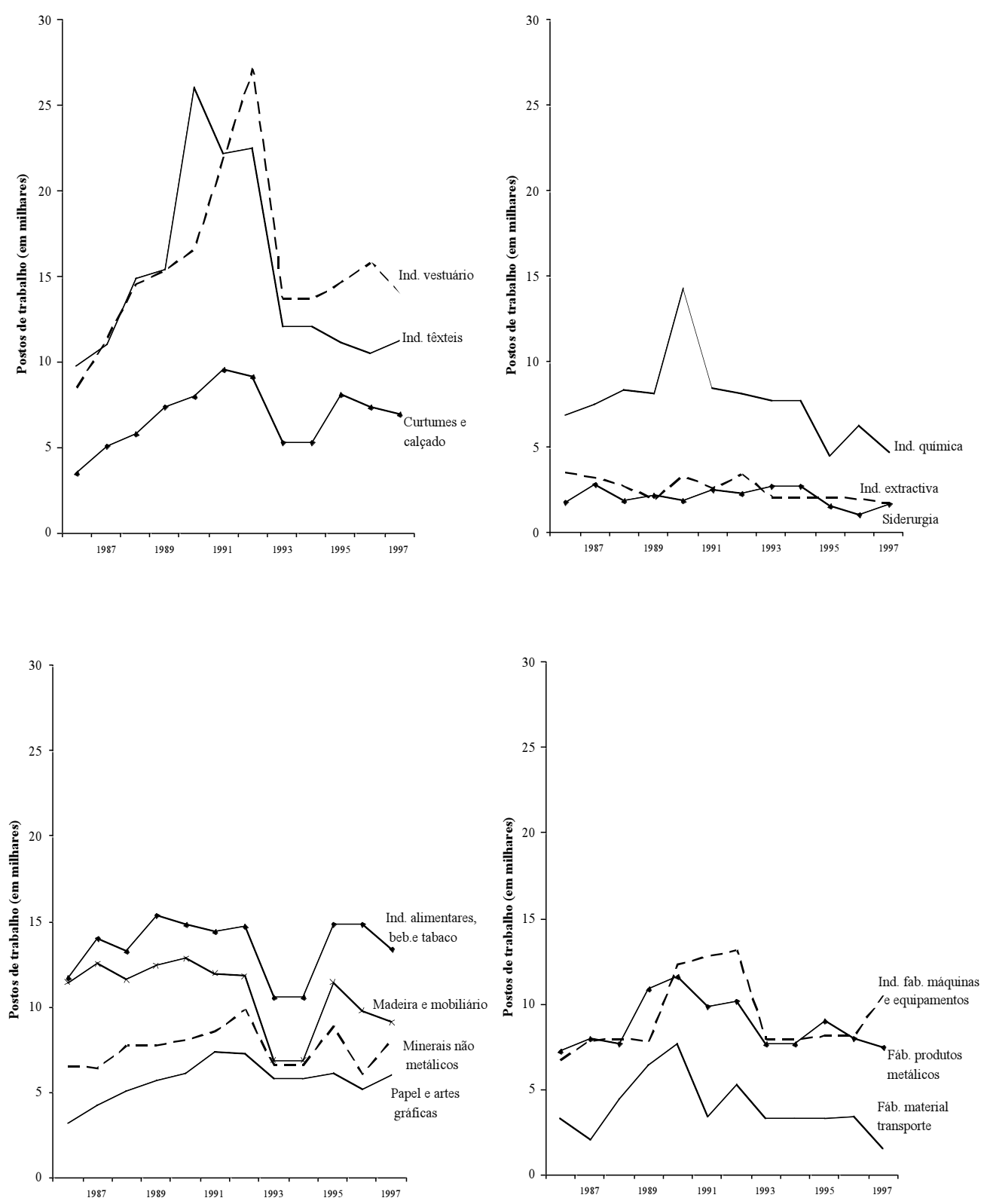

DETEFP (1999), com tratamento próprio.

Fig. 3 - Evolução da destruição de emprego industrial, por ramo, em Portugal, 1986-1998.

Fig. 3-Evolution of industrial job destruction by industrial branch in Portugal 1986-1998. 
O facto assinalável é que, desde a adesão de Portugal à Comunidade Económica Europeia, em 1986, até finais dos anos 1990, não se registaram mudanças estruturais na base industrial do país (fig. 4). Com efeito, a análise dos fluxos de criação e de destruição de emprego permite confirmar que a estrutura industrial apresentou poucas variações no período em análise, verificando-se que as actividades mais dinâmicas na criação de emprego foram também as mais destruidoras ${ }^{6}$.

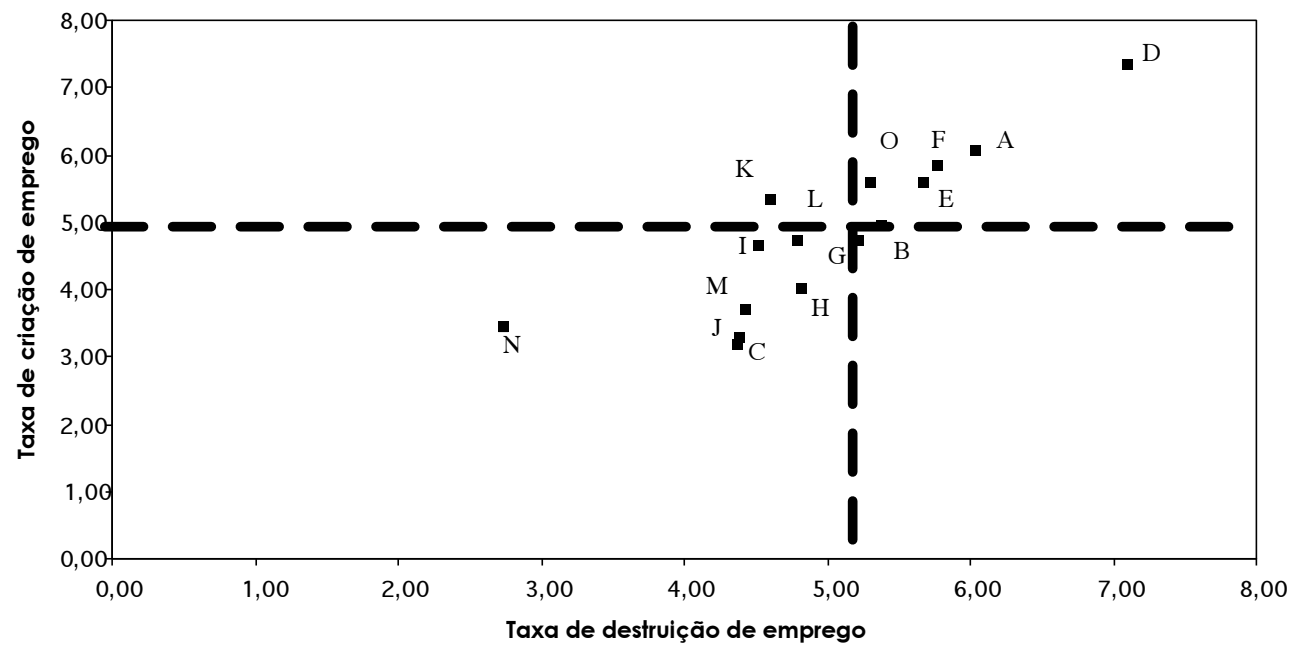

\section{Legenda:}

A - Indústria extractiva; B - Ind. Alimentares, das Bebidas e Tabaco; C - Ind. Têxteis; D - Ind. do Vestuário; E - Ind. do Calçado e Couro; F - Ind. da Madeira e Mobiliário; G - Ind. do Papel e Artes Gráficas; H - Indústria Química; I - Ind. dos Produtos Minerais não Metálicos; J - Ind. Metalúrgica de Base; K - Fabricação de Produtos Metálicos (excep. maq. e equip.); L - Fabricação de Máquinas e Equipamentos; M - Fabricação de Material de Transporte; N - Fabricação de Instrumentos Profissionais; O - Outras Indústrias Transformadoras

DETEFP (1999), com tratamento próprio.

Fig. 4 - Taxas globais de criação e destruição de emprego de emprego industrial, por ramo, em Portugal, 1986-1998.

Fig. 4-Global rates of industrial job creation and destruction by branch in Portugal, 1986-1998.

6 O coeficiente de correlação de Pearson (r) entre a taxa de criação e a de destruição de emprego é de 0,86 . 


\section{Espaços da indústria em mudança}

Detectam-se importantes assimetrias espaciais ao nível da criação e destruição de emprego industrial. Ilustrando uma tendência que se iniciou pelo menos nos anos 1970 (FERRÃo, 1987), a Área Metropolitana de Lisboa (AML) perdeu emprego industrial em valor absoluto, verificando-se no caso da Grande Lisboa um saldo negativo entre a criação de emprego em novos estabelecimentos e a destruição de emprego por encerramento, bem como um saldo negativo entre o emprego criado e destruído em estabelecimentos existentes (quadro VII). A continuação do processo de reestruturação industrial e o desmantelamento da indústria pesada contribuíram muito significativamente para a destruição de emprego na AML (BAPTISTA, 1989; FonSECA, 1998). Verifica-se na Área Metropolitana do Porto (AMP) uma tendência semelhante à da Grande Lisboa, cuja diminuição absoluta do emprego industrial, acompanhada também pelo saldo negativo entre criação e destruição de emprego, permite confirmar o desinvestimento neste sector na região.

Mas o declínio do emprego industrial pode relacionar-se com as alterações de uso nas áreas urbanas, que se traduzem por um movimento centrífugo dos

Quadro VII - Emprego criado e destruído por abertura, encerramento, relocalização, expansão e contracção de estabelecimentos industriais em Portugal, 1986-1998.

Table VII - Jobs created and destroyed as a result of openings, closings, relocations, expansions and contractions of manufacturing plants in Portugal, 1986-1998.

\begin{tabular}{|c|c|c|c|c|c|c|c|}
\hline & Emp. Ind. & $\begin{array}{c}\text { Emp. } \\
\text { Criado } \\
\text { Novos } \\
\text { Estab. } \\
(1986-1998)\end{array}$ & $\begin{array}{c}\text { Emp. } \\
\text { Destruido } \\
\text { Estab. Enc. } \\
(1986-1998)\end{array}$ & $\begin{array}{c}\text { Saldo } \\
\text { Emprego } \\
\text { Dest. } e \\
\text { Emprego } \\
\text { Criado }\end{array}$ & $\begin{array}{c}\text { Saldo } \\
\text { Emp. Dest. } \\
\text { Emprego } \\
\text { Criado em } \\
\text { Estab. } \\
\text { Existentes }\end{array}$ & $\begin{array}{c}\text { Emp. Ind. } \\
\text { (1998) }\end{array}$ & $\begin{array}{c}\text { Emp. } \\
(1986-1998)\end{array}$ \\
\hline Portugal (Continente) & 863249 & 598757 & 629073 & -30316 & 14792 & 847725 & -15524 \\
\hline Norte & 428716 & 327131 & 326875 & 256 & 25271 & 454243 & 25527 \\
\hline Ave & 115335 & 73799 & 76397 & -2598 & 679 & 113416 & -1919 \\
\hline Grande Porto & 164903 & 98555 & 117539 & -18984 & -16814 & 129105 & -35798 \\
\hline Centro & 145049 & 88715 & 88813 & -98 & 18885 & 163836 & 18787 \\
\hline Serra da Estrela & 5750 & 1886 & 3159 & -1273 & -1537 & 2940 & -2810 \\
\hline Cova da Beira & 12843 & 5029 & 5206 & -177 & -1779 & 10887 & -1956 \\
\hline Lisboa e Vale do Tejo & 258774 & 156960 & 186738 & -29778 & -28277 & 200719 & -58055 \\
\hline Grande Lisboa & 148228 & 79905 & 98476 & -18571 & -36797 & 92860 & -55368 \\
\hline Península de Setúbal & 54032 & 34492 & 42464 & -7972 & -3817 & 42243 & -11789 \\
\hline Alentejo & 22086 & 17943 & 19548 & -1605 & 693 & 21174 & -912 \\
\hline Algarve & 8624 & 8008 & 7099 & 909 & -1780 & 7753 & -871 \\
\hline
\end{tabular}

DETEFP (1999); com tratamento próprio. 
estabelecimentos localizados em espaços mais centrais. Um estudo pioneiro de Alves e MADRUga (1996) evidencia precisamente que a deslocalização dos estabelecimentos é particularmente forte na AML e moderada na AMP, e conclui que se trata principalmente de uma relocalização de proximidade, envolvendo municípios destas áreas e uma coroa envolvente, em resultado de factores de repulsão ou pela necessidade de expansão da actividade. Com efeito, os autores confirmam a existência de uma relação entre a deslocalização de estabelecimentos e o aumento de emprego. Por outro lado, como referem QueIRós et al. (2002), ao abandonarem aquelas áreas urbanizadas para territórios mais periféricos, as empresas não só superam um conjunto de inconvenientes resultantes da aglomeração, como retiram outras vantagens decorrentes da relocalização, designadamente a valorização imobiliária do sítio mais central. Há, deste modo, evidências de declínio industrial nas áreas metropolitanas que não podem ser explicadas exclusivamente por uma crise da actividade.

Para além da dinâmica negativa das áreas metropolitanas, o Vale do Ave, Serra da Estrela, Cova da Beira e o Alentejo Litoral registaram, no período em análise, uma clara tendência para o desinvestimento industrial, associado ao declínio das actividades têxtil/vestuário nas três primeiras áreas e à reestruturação das indústrias da petroquímica em Sines.

As áreas do país que observaram maiores ganhos de emprego industrial são os prolongamentos da AMP - incluindo as NUT III Cávado, Tâmega e Entre Douro e Vouga - o Baixo Vouga, Dão-Lafões e o Pinhal Litoral na região Centro, e o Oeste na região de Lisboa e Vale do Tejo. Em todas estas áreas se verificou um saldo positivo entre o emprego criado e destruído em estabelecimentos existentes, embora não se possa afirmar o mesmo em relação ao saldo entre emprego criado em novos estabelecimentos e o destruído por encerramento de estabelecimentos, com valores positivos apenas nas NUT III Cávado, Tâmega e Baixo Vouga. Estas são claramente as três principais áreas ganhadoras do país em relação ao investimento industrial.

Em seguida, procede-se a uma breve análise espacial restrita aos fluxos de criação e de destruição de emprego, por serem inequivocamente o resultado de processos de investimento e desinvestimento. A análise contrastada dos dois tipos de fluxo dá-nos uma indicação da resposta das regiões ao fenómeno do desinvestimento (fig. 5). A análise do padrão espacial dos fluxos de criação e de destruição de emprego permite verificar que as regiões polarizadas por Lisboa e pelo Porto registaram uma tendência clara e persistente de destruição de emprego industrial que não foi compensada pela criação de postos de trabalho em novos estabelecimentos do sector secundário. Não parece haver dúvidas quanto à tendência para a desindustrialização da base económica das duas principais regiões do país, que estimulou, no entanto, a expansão da indústria em áreas envolventes, em resultado da deslocalização de estabelecimentos (GoMEs, 2001).

É a norte que se concentram as regiões onde o saldo global entre a criação e a destruição de emprego é mais positivo. Em algumas destas regiões a indús- 


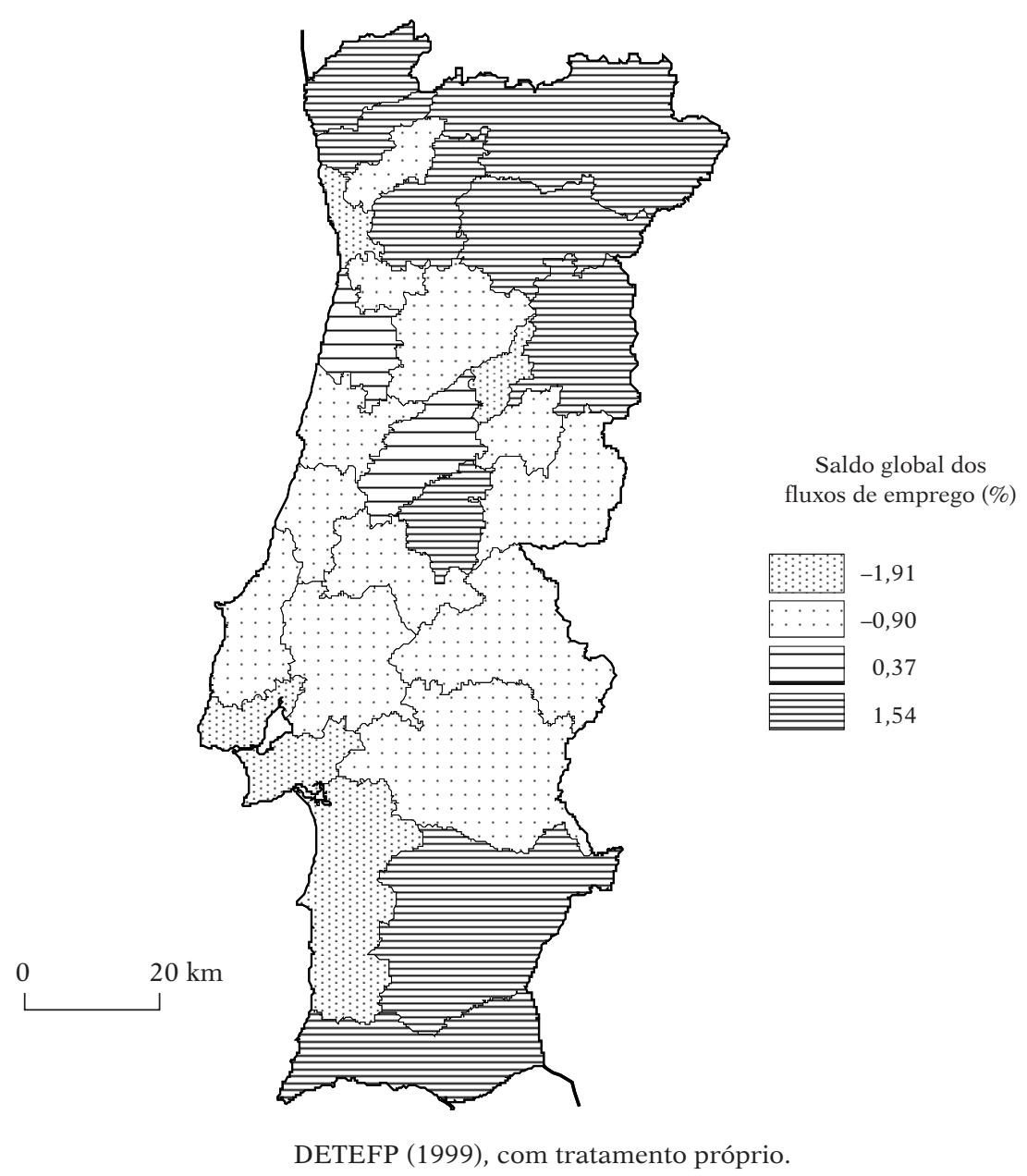

Fig. 5 - Balanço entre as taxas globais de criação e destruição de emprego industrial, por região (NUT III), em Portugal Continental, 1986-1998.

Fig. 5 - Balance between global rates of industrial job creation and destruction by region (NUT III), Continental Portugal, 1986-1998.

tria tem um peso relativamente elevado, sobretudo na fachada litoral, apesar de nem todas as áreas registarem ganhos absolutos no emprego industrial, como é o caso do Vale do Ave. No Interior Norte, o comportamento da actividade industrial caracterizou-se por ganhos líquidos elevados de emprego, tal como no Algarve e no Baixo Alentejo. Refira-se que este comportamento ocorre em espaços onde o emprego industrial é menos relevante face ao volume total de emprego e expressa uma expansão das actividades industriais mais tradicionais em espaços de baixos salários (Dias e VALE, 2003). 
A persistência da estrutura industrial fez-se acompanhar por mudanças no mapa do emprego do sector em Portugal. A redução da concentração do emprego não é, todavia, tão ampla ao ponto de alterar as clivagens espaciais entre o litoral e o interior. Com efeito, as alterações na geografia do emprego industrial induzidas pelo desinvestimento compreendem no essencial a regressão desta actividade em ambas as áreas metropolitanas e em áreas de especialização industrial no têxtil/vestuário, como no Vale do Ave, Cova da Beira e Serra da Estrela. A expansão destas actividades em áreas rurais do Norte Litoral (Cávado e Tâmega) e até o recurso a trabalhadores imigrantes indiciam a procura de reservas de mão-de-obra de custos ainda mais baixos, materializando uma estratégia de manutenção de um modelo de competitividade desajustado para a economia portuguesa face à integração de países emergentes no sistema internacional de subcontratação. Em conclusão, os sinais de diminuição das disparidades regionais de emprego industrial não parecem ser suficientemente duráveis para se falar de uma nova geografia industrial, parecendo tratar-se de uma mudança que em breve poderá entrar em colapso por se basear na expansão de actividades industriais intensivas em trabalho mal remunerado de difícil integração em cadeias de valor global.

\section{PRINCIPAIS CASOS DE DESINVESTIMENTO INDUSTRIAL ESTRAN- GEIRO EM PORTUGAL ${ }^{7}$}

A integração de Portugal no espaço económico europeu e a realização do Mercado Único contribuíram para que o investimento directo estrangeiro (IDE) atingisse níveis muito elevados no país, tendo crescido de $0,6 \%$ do PIB para 3,7\% em 1990. Este ciclo expansivo foi interrompido em 1992 como consequência da recessão económica europeia e da apreciação real da moeda nacional, assim como da abertura das economias do Leste da Europa. Sem uma tendência de evolução estabilizada, o IDE volta a crescer em 2000 para valores semelhantes aos de 1990, porém, detecta-se uma mudança estrutural na sua composição. Segundo LeITE et al. (2001), a entrada de capital estrangeiro tem-se dirigido para sectores como o imobiliário, serviços prestados às empresas, transportes e comunicações e comércio, verificando-se um declínio do IDE na indústria transformadora e mesmo nas actividades financeiras.

O saldo do IDE na indústria tem vindo a diminuir em Portugal, tendo-lhe cabido uma fatia de 46\% do saldo do IDE em Portugal em 1994 contra apenas $2 \%$ em 2000. Consequentemente, o stock de investimento estrangeiro na indústria transformadora decaiu de 34,3\% para 19,7\% entre 1993 e 2000. LeITE et al. (2001) destacam também a elevada turbulência do IDE nesta actividade,

7 Este ponto desenvolve e actualiza uma comunicação apresentada por um dos autores (VALE, 2002). 
expressa pela manutenção elevada de fluxos de investimento e de desinvestimento. A redução da duração do investimento na indústria transformadora revela-se negativa para a economia nacional, sobretudo porque acarreta uma diminuição dos spillovers e atenua a mudança estrutural. Na verdade, os casos de desinvestimento estrangeiro na indústria são cada vez mais numerosos e, desde os investimentos da Autoeuropa e da Siemens, ainda não se concretizou nenhum outro grande projecto de IDE neste sector em Portugal (VALE, 2002).

Num estudo acerca do desinvestimento estrangeiro em Portugal entre 1983 e 1989, Mata e Portugal (2000) analisam duas formas de saída das multinacionais: encerramento da unidade ou venda da participação (os autores designam este processo de "desinvestimento"). Concluem que há uma maior probabilidade de encerramento da filial quando o modo de entrada foi pela via da criação de um novo estabelecimento, verificando-se uma tendência para a venda da participação nos casos de entrada por via de aquisição de estabelecimentos existentes.

Os principais casos de desinvestimento estrangeiro na indústria em Portugal ocorreram após a abertura das economias do Leste da Europa, verificando-se uma deslocalização de actividades industriais para estes países com mão-de-obra qualificada e de menor remuneração, ainda que a dimensão do mercado, enquanto factor de localização industrial, não seja despicienda (MAIA, 2000). De facto, entre os 20 principais casos de desinvestimento, 12 ocorreram desde o ano 2000 até ao presente e destes 11 dizem respeito às indústrias do vestuário ou do calçado, tendo sido destruídos mais de 3200 postos de trabalho (quadro VIII). Este padrão contrasta fortemente com o tipo de encerramento de filiais estrangeiras antes do ano 2000, marcado por um desinvestimento moderado e sectorialmente diversificado, que nem sempre teve na sua origem motivações relacionadas com os custos de trabalho, casos da Renault, Valmet, Firestone, Tisep e Nokia (VALE, 2002).

Pela relevância e actualidade do problema do desinvestimento estrangeiro nas indústrias intensivas em trabalho do vestuário e do calçado, que afecta diversas regiões do país, pode identificar-se uma tendência clara de perda de competitividade dos factores de localização tradicionais. São actividades que não exigem um elevado nível tecnológico e onde o custo da mão-de-obra representa uma parte elevada nos custos de produção. Sendo o custo do factor trabalho mais elevado em Portugal por comparação com alguns países emergentes, verifica-se que a deslocalização destas unidades de capital estrangeiro não é um meio de ampliar a internacionalização da produção, mas antes uma consequência do problema de competitividade-preço associado aos custos de mão-de-obra (DUARTE, 2001).

As empresas de capital estrangeiro podem substituir a produção nas suas unidades encerradas seguindo estratégias diferenciadas mas eventualmente complementares: aumento de capacidade industrial em unidades existentes; criação de novos estabelecimentos; formação de redes de subcontratação. O recurso à subcontratação tem sido uma das formas privilegiadas de substituição da produção na indústria do vestuário e do calçado. Aliás, Portugal bene- 
Quadro VIII - Casos de desinvestimento estrangeiro em Portugal.

Table VIII - Foreign divestment in Portugal.

\begin{tabular}{|c|c|c|c|c|c|}
\hline Empresa & Estabelecimento & Localização & Actividade & $\begin{array}{l}N .^{o} \text { de postos } \\
\text { de trabalho }{ }^{(a)}\end{array}$ & $\begin{array}{c}\text { Datade } \\
\text { encerramento }\end{array}$ \\
\hline Seagate & Seagate & Palmela & $\begin{array}{c}\text { Fab. de Cabeças } \\
\text { de Memória Magnéticas } \\
\text { para Computadores }\end{array}$ & 870 & 1992 \\
\hline Firestone & $\begin{array}{c}\text { Firestone } \\
\text { Portuguesa }\end{array}$ & Alcochete & Fab. Pneus & 450 & 1992 \\
\hline Nokia & Nokia & Cascais & $\begin{array}{l}\text { Tab. Electrónica } \\
\text { de Consumo }\end{array}$ & 282 & 1992 \\
\hline Valmet & Valmet & Montijo & Produção Tractores & 35 & 1997 \\
\hline Renault & Renault & Setúbal & Montagem Automóveis & 590 & 1998 \\
\hline Nestlé & Longa Vida & Matosinhos & Fab. Produtos Alimentares & \pm 100 & 1998 \\
\hline \begin{tabular}{|l} 
Texas \\
Instruments / \\
Samsung \\
\end{tabular} & Tisep & Maia & Semicondutores & 750 & 1999 \\
\hline Grundig & \begin{tabular}{|c|} 
Grundig \\
Electrónica e OEM \\
\end{tabular} & Braga & $\begin{array}{l}\text { Fab. Aparelhos hi-fi } \\
\text { e de telecomunicaçóes }\end{array}$ & 107 & 1999 \\
\hline Samsung & Samsung Portugal & Sintra & $\begin{array}{l}\text { Fab. Componentes } \\
\text { Electrónicos }\end{array}$ & 290 & 2000 \\
\hline Clarks & Clarks & Arouca & Calçado & 368 & 2000 \\
\hline Goela Fashion & Goela Fashion & Santo Tirso & Vestuário & 137 & 2001 \\
\hline Camilla & Confecções Camilla & Castelo Branco & Vestuário & 167 & 2001 \\
\hline ERES & ERES & Fundão & Vestuário & 470 & 2002 \\
\hline \begin{tabular}{|l|} 
Scottwool \\
\end{tabular} & Scottwool & Figueira da Foz & Têxtil & \pm 100 & 2002 \\
\hline Polgat & Bagir & Coimbra & Vestuário & \pm 300 & 2002 \\
\hline Vestus & Vestus & Corroios, Setúbal & Vestuário & 414 & 2002 \\
\hline \begin{tabular}{|l|} 
Schuh Union \\
\end{tabular} & Schuh Union & Maia & Calçado & 440 & 2002 \\
\hline Melka & Melka & Palmela & Vestuário & 170 & 2002 \\
\hline Clarks & Clarks & Castelo de Paiva & Calçado & 588 & 2003 \\
\hline $\begin{array}{l}\text { Gerry Weber } \\
\text { International } \\
\text { AG }\end{array}$ & Gerry Weber & Figueiró dos Vinhos & Vestuário & 140 & 2003 \\
\hline
\end{tabular}

(a) Referente à data de encerramento

Expresso, Público, Diário de Notícias, Lusa, FREITAS (1998), EIRO (European Industrial Relations Observatory)

ficiou no passado da estratégia de subcontratação dos grupos internacionais, surgindo a crise actual em muitas empresas nacionais, particularmente do vestuário, como um resultado da alteração nas redes de subcontratação internacionais, que beneficiam claramente o Sudeste Asiático e Europa do Leste.

Estas evidências de desinvestimento estrangeiro nas indústrias de vestuário e de calçado indiciam uma alteração da posição de Portugal na divisão internacional do trabalho, revelando-se insustentável a manutenção de um modelo de competitividade baseado nos baixos custos do trabalho à medida que se acentua a integração económica ao nível internacional. Todavia, esta leitura não pode esconder outro aspecto igualmente crítico para o desenvolvimento do país, que só é perceptível se adoptarmos uma perspectiva de análise baseada no conceito de cadeia de valor global. Segundo KAPLinsKY (2000), a cadeia de valor global compreende o conjunto de todas as actividades necessárias para o fornecimento 
de um bem ou serviço, que vão desde a concepção à comercialização, passando pelas diferentes fases de produção e pelo marketing. Com a globalização, as cadeias de valor alargaram-se a outras regiões em busca de vantagens económicas e tornaram-se mais complexas as suas formas de governância (funções, regras, poder,...; HUDSON, 2001). O vestuário e o calçado são claramente cadeias de valor global, compreendendo diferentes funções e agentes que geram valor acrescentado desigual e, como é sabido, os estabelecimentos das empresas estrangeiras localizados em Portugal desenvolvem sobretudo funções menos qualificadas e muito dependentes do custo do trabalho.

$\mathrm{O}$ que parece ter-se passado nestes sectores em Portugal reflecte também a incapacidade de muitos agentes económicos nacionais em melhorar a sua posição nas cadeias de valor global, quer por via da melhoria de processos, do produto, da mudança de funções (design, marketing, comercialização,...) ou até pela entrada em novas cadeias de valor. Este problema pode ser confirmado pela perda de quota de mercado da exportação portuguesa nas importações europeias de vestuário de origem europeia, comprovando que os parceiros europeus têm maior capacidade para acrescentar valor ao produto para além da própria produção industrial (BESSA e VAZ, 2002). Assim, o problema de competitividade-preço associado aos custos de mão-de-obra não é uma ameaça per si, só se revelando um obstáculo quando é acompanhado pela fraca capacidade para melhorar a posição nas cadeias de valor global. E, neste ponto, as políticas públicas sectoriais poderiam ter estimulado mais incisivamente a mudança.

\section{NOTA FINAL}

As transformações no espaço económico internacional têm precipitado a queda do emprego industrial nas actividades mais intensivas em trabalho, a que se associa uma mudança da organização do espaço industrial em Portugal.

O declínio do emprego industrial configura um caso de desinvestimento sistemático e generalizado na capacidade produtiva de base em alguns segmentos nas duas áreas metropolitanas do país, sendo uma tendência que se iniciou pelo menos nos anos 1970 na AML e na década de 1980 na AMP. Do mesmo modo, as áreas de forte especialização monoindustrial atravessaram uma fase de desinvestimento resultante da perda de competitividade-preço da mão-de-obra, em virtude dos custos do trabalho representarem uma parte significativa dos custos de produção no vestuário e no calçado, conforme comprovam os casos de encerramento de estabelecimentos participados por capital estrangeiro. Esta tendência é mais visível desde finais da década de 1990, quando alguns países emergentes passaram a integrar redes de produção internacionais, por via do acolhimento de unidades deslocalizadas ou pela participação nas redes de subcontratação.

Outra mudança na geografia industrial portuguesa desde finais dos anos 1980 reporta-se à dinâmica de crescimento de alguns espaços limítrofes às áreas 
mais industrializadas do Noroeste, casos das NUT III do Tâmega e do Cávado, onde a expansão das indústrias de vestuário e calçado indiciam um prolongamento do modelo de industrialização assente em baixos salários. Na verdade, a mudança da estrutura industrial não foi mais profunda devido a esta expansão do sistema produtivo do têxtil/vestuário e do calçado em áreas periféricas do país.

Num período mais recente, os casos de desinvestimento estrangeiro, nas indústrias do vestuário e calçado, confirmam a insustentabilidade do modelo de competitividade português assente no baixo custo da mão-de-obra. Por outro lado, a incapacidade dos agentes económicos em se reposicionarem na cadeia de valor global respectiva, nomeadamente através da aposta em funções de maior valor acrescentado, vem acentuar as debilidades de Portugal na divisão internacional do trabalho, revelando-se complexa e difícil esta fase de transição da economia portuguesa.

\section{BIBLIOGRAFIA}

Alves, M. B. e Madruga, P. (1996) - Reestruturação urbana e tendências de relocalização das empresas na Área Metropolitana do Porto nos anos 80. Sociedade e Território, 23: 62-74.

Bairrada, M. (2000) - Enriquecimento da Actividade Económica em Emprego a Nível Macro e Micro. Observatório do Emprego e Formação Profissional, Lisboa.

Baptista, A. M. (1989) - Perspectivas de desenvolvimento económico da Área Metropolitana de Lisboa. Sociedade e Território, 10/11: 43-48.

Benito, G. (1997) - Why are foreign subsidiaries divested? A conceptual framework. In I. BJöRKMAN e M. ForSGREN (eds.) - The Nature of the International Firm. Copenhagen Business School Press, Copenhaga: 309-334.

Benko, G. e Lipietz, A. (1992) (eds.) - Les Régions qui gagnent. Districts et réseaux: les nouveaux paradigmes de la géographie économique. PUF, Paris.

Bessa, D. e VAz, P. (2002) - Um Contributo para um Plano Estratégico para a Indústria Têxtil e do Vestuário Portuguesa. APIM, Porto.

Blackaby, F. (1981) (ed.) - Deindustrialization. Heinemann, Londres.

Bluestone, B. e Harrison, B. (1982) - The Deindustrialization of America. Plant Closings, Community Abandonment, and the Dismantling of Basic Industry. Basic Books, Nova Iorque.

BodDEWYN, J. J. (1979) - Foreign divestment: magnitude and factors. Journal of International Business Studies, 10: 21-27.

Clark, G. L. e Wrigley, N. (1997)- Exit, the firm and sunk costs: reconceptualizing the corporate geography of divestment and plant closure. Progress in Human Geography, 21 (3): 338-358.

Costa, E. e Costa, N. (1996) - Compatibilização da CAE Rev. 1 com a CAE Rev. 2. Uma proposta de trabalho. Finisterra - Revista Portuguesa de Geografia, XXXI (62) Lisboa: 123-131. 
Dias, R. e Vale, M. (2003) - Tendências Espaciais de Desinvestimento. WP5, Projecto DivesT, (polic.).

DuARte, A. P. (2001) - As deslocalizações industriais no contexto da globalização. In J. ReIs; I. Baganha (eds.) - A Economia em Curso. Contextos e Mobilidades. Edições Afrontamento, Porto: 173-221.

Duhaime, I. e Grant, J. (1984) - Factors influencing divestment decision-making: evidence from a field study. Strategic Management Journal, 5: 301-318.

FERrão, J. (1987) - Indústria e Valorização do Capital. Uma Análise Geográfica. CEG, Universidade de Lisboa, Lisboa.

FONSECA, M. L. (1998) - Lisboa: reestruturação produtiva e transformações urbanísticas numa capital periférica. In J. GASPAR e M. VALE (eds.) - Desenvolvimento Industrial e Território. CCR Centro/CEG, Coimbra: 151-176.

Freitas, J. A. (1998) - Determinantes do desinvestimento em Portugal. Documentos de Trabalho, 13, GEPE/Ministério da Economia.

Gomes, H. (2001) - Reestruturação e Expansão Industrial na Área Metropolitana de Lisboa. A Emergência de Novos Territórios. Os Casos de Sintra e Alenquer. Dissertação de Mestrado em Geografia Humana, Faculdade de Letras da Universidade de Lisboa. Lisboa.

Hudson, R. (2001) - Commodity Chains and Flows of Value: Exploring the Links Between Corporate Strategies, Governance Processes and Regional Economic Development in Europe. In M. VALE (ed.) - DivesT: Desinvestimento e Impactos Económicos, Sociais e Territoriais. Actas/Proceedings Workshop DivesT. Estudos para o Planeamento Regional e Urbano, n. ${ }^{\circ}$ 54. Centro de Estudos Geográficos, Lisboa: 11-50.

KAPLINSKY, R. (2000) - Globalisation and unequalisation: What can be learned from value chain analysis? Journal of Development Studies, 37 (2): 117-146.

LARIMO, J. (1997) - Determinants of divestments in foreign production operations made by finnish firms in OECD countries. In K. Macharzina; M. J. Oesterle e J. Wolf (eds.) Global Business in the Information Age. EIBA-EXTEC, Stuttgart: 354-379.

Leite, A. N.; Machado, J. A. e Cúrdia, V. (2001) - Portugal como Destino do Investimento Estrangeiro. Estado da Competitividade da Economia Portuguesa. Câmara do Comércio Americana em Portugal, Lisboa.

Maclachlan, I. (1992) - Plant closure and market dynamics: competitive strategy and rationalization. Economic Geography, 68 (2): 128-145.

MaIA, P. (ed.) (2000) - Deslocalização de Empresas e Emprego. Observatório do Emprego e Formação Profissional, Lisboa.

Mariotti, S. e Piscitello, L. (1977) - Divestment as failure or part of a restructuring strategy: evidence from Italian MNEs. In K. Macharzina; M. J. Oesterle e J. Wolf (eds.) - Global Business in the Information Age. EIBA-EXTEL, Stuttgart: 382-404.

Martin, R. e Rowthorn, B. (1986) (eds.) - The Geography of Deindustrialization. Macmillan, Londres.

Massey, D. (1984) - Spatial Divisions of Labour. Social structures and the geography of production. Macmillan, Londres.

Massey, D. e Meegan, R. (1982) - The Anatomy of Job Loss. Methuen, Londres. 
Mata, J. e Portugal, P. (2000) - Closure and divestiture by foreign entrants: the impact of entry and post-entry strategies. Strategic Management Journal, 21: 549-562.

Pires, I. (1994) - A Teia e a Trama nas Indústrias Têxtil e do Vestuário. Dissertação de Doutoramento, Universidade de Lisboa. Lisboa.

Queirós, M.; Henriques, E. B.; Gomes, H. e SoAres, P. (2002) - Desinvestimento e Impactos Territoriais. WP2, Projecto DivesT (polic.).

Simões, V. C. (2001) - Divestment by Foreign-Based Firms: Endogenous versus Contextual Factors. In M. VALE (ed.) - DivesT: Desinvestimento e Impactos Económicos, Sociais e Territoriais. Actas/Proceedings Workshop DivesT. Estudos para o Planeamento Regional e Urbano, n. ${ }^{\circ}$ 54. Centro de Estudos Geográficos, Lisboa: 93-119.

SoAREs, P. (2001) - Declínio do Emprego na Siderurgia Portuguesa: Estratégias Empresariais e Características Regionais. In M. VALE (ed.). - DivesT: Desinvestimento e Impactos Económicos, Sociais e Territoriais. Actas/Proceedings Workshop DivesT. Estudos para o Planeamento Regional e Urbano, n. ${ }^{\circ}$ 54. Centro de Estudos Geográficos, Lisboa: 51-72.

VAle, M. (2001) - Desinvestimento e território: um quadro conceptual de análise. In M. Vale (ed.) - DivesT: Desinvestimento e Impactos Económicos, Sociais e Territoriais. Actas/ Proceedings Workshop DivesT. Estudos para o Planeamento Regional e Urbano, n. ${ }^{\circ} 54$. Centro de Estudos Geográficos, Lisboa: 251-289.

VALE, M. (2002) - Divestment of foreign entrants: some less successful stories of European integration. Comunicação ao $4^{\text {th }}$ European Urban and Regional Studies Conference, (Re)placing Europe: economies, territories and identities, Universidade Autónoma de Barcelona. Barcelona (polic.).

Watts, H. D. e Stafford, H. A. (1986) - Plant closure and the multiplan firm: some conceptual issues. Progress in Human Geography, 10 (2): 206-227.

WATTS, H.D. (1991) - Plant Closures in Urban Areas: Towards a Local Policy Response. Urban Studies, 28 (5): 803-817. 